this were correct, it has little relation to conditions as they occur in bloat where chewing by the animal does not break up the plant fibre to such an extent. When we compared fermentation-rates of clover juice with whole boluses collected from the cardias of cattle fed fresh clover, rates were similar and no greater than those observed with equivalent amounts of juice. Washing of the boluses to remove saliva and juice markedly lowered the rate of fermentation.

Our results indicate that the plant substances responsible for the initial rapid gas-production after the ingesta of legumes are associated with the plant juices. Hence it seems unlikely that the pectic substances and hemicelluloses closely associated with the fibre fraction can be important in this regard.

J. M. BoDA*

Plant Chemistry Division,

A. T. JoHns

Department of Scientific

and Industrial Research,

Palmerston North, Now Zealand.

- Fulbright Research Scholar from Department of Animal Husbandry, University of California, Davis. Conrad, H. R., Pounden, W. D., Bentley, O. G., and Fetter, A. W.,
J. Dairy Sci., 41, 1586 (1958).

2 Cole, H. H., Mead, S. W., and Regan, W. M., J. Animal Sci., 2, 285 (1943).

Blake, J. T., Jacobson, N. L., and Allen, R. S., J. Dairy Sci., 88, 606 (1955).

' Ferguson, W. S., and Terry, R. A., J. Agric. Sci., 46, 257 (1955).

'Lindahl, I. L., Dougherty, R. W., and Davis, R. E., U.S. Dairy A8soc. Tech. Bull., 1161, 15 (1957). (1957).
Moore, C. Hall, V. A., and Dracy, A. E., J. Dairy Sci., 40, 616

' Newbold, R. P., N.Z. J. Sci. Technol., Sec. A, 86, 285 (1954).

Methods of Analysis of the Association of Official Agricultural Chemists, sixth ed. (Washington, D.C., 1945).

\section{Insect Pollination of Plantago lanceolata L.}

IN Britain, Plantago lanceolata is regarded as windpollinated ${ }^{2}$ and is figured by McLean and IvimeyCook $^{2}$ as a typical example of a long-filament-type wind-pollinated species. It was therefore of interest to observe that around Brisbane this long-filament form is regularly worked for pollen by the honey bee wherever a dozen or so spikes are flowering within a few feet of each other.

The bees alight on the flowering spikes at or below the 'collar' of flowers with exserted anthers and crawl through them to the level of those with receptive stigmas. An examination of the pollen loads of sevoral bees captured from flowering spikes showed that most of the pollen present had come from the anthers of $P$. lanceolata. The visits of the bees to the flowering spikes are not haphazard, and the same bee can readily be followed as it flies from plant to plant collecting pollen. The bees were observed visiting the species from early November 1960 until mid-April 1961, when the obsorvation site was unfortunately destroyed.

During this period the weather was mild, and the temperature was never below $55^{\circ} \mathrm{F}$. according to the records of the Brisbane Weather Bureau (courtesy of the Director). Under these conditions the bees are active early in the morning, and are foraging when the anthers of $P$. lanceolata split, exposing their pollen. Though some pollen may be shed and dis. persed by wind at this time, a good deal remains within the anther-lobes, and is later gathered by the bees; before midday the anthers are empty and bees ignore the species until the following day.
Where the climate is cooler, as in Britain, anthesis still occurs in the early morning ${ }^{3}$ and it is suggested here that in such places the species may be predominantly pollinated by wind due to most of the pollen being shaken from the anthers and dispersed before it is warm enough for the bees to be foraging. This would account for $P$. lanceolata being both wind- and insect-pollinated around Brisbane, but only wind. pollinated in cooler climates.

From these observations it would appear that in this species specialized floral structure is not necessarily required for insect pollination to occur. Nevertheless, flowers especially modified for insect pollination have been reported. Darwin", quoting Delpino, states that, in Italy, $P$. lanceolata has flowers of three kinds, grading from anemophilous to entomophilous.

The existence of two pollination mechanisms, sometimes but not necessarily accompanied by differences in floral structure, may be responsible for some of the confusion in the literature regarding the pollination mechanism of other species in the genus. For example, in Britain $P$. media has recently been recorded as insect-pollinated by Clapham et al. ${ }^{1}$ but as windpollinated by McLean and Ivimey-Cook ${ }^{2}$. Here it could be that each of the two authorities cited has observed plants with different forms of flowers, for $P$. media is reported to be florally dimorphic ${ }^{5}$ with one form adapted for wind-and the other for insect. pollination. Alternatively, it could be that either or both forms of flower occur in Britain and that each is both wind- and insect-pollinated, leading to the divergent statements quoted.

Further observations are required to determine exactly the pollination mechanism or mechanisms for this and other species in the genus.

Department of Botany,

\section{H. T. Cliffford}

University of Queensland, Brisbane.

${ }^{1}$ Clapham, A. R., et al., Flora of the British Isles (Camb. Univ. Press, 1057).

${ }^{8}$ McLean, R. C., and Ivimey-Cook, W. R., Textbook of Theoretical Botany, 2, 1289, 1281 (London, 1956).

s Hyde, H. A., and Williams, D. A., New Phyt., 42 (2), 271 (1966).

- Darwin, O., The Different Forms of Flowers on Plants of the same Species (London, 1877).

- Harms, H., and Reiche, C., Die natiurlichen Pfanzenfamilien (Plantaginaceae), 4 (3) $G, 363$ (1895).

\section{Appendages on the Spores of Myrothecium verrucaria}

DuRING an investigation on the degradation of cotton by Myrothecium verrucaria it was observed that spores produced by cultures of this fungus showed under the microscope an unexpected appendage or 'tail' which is illustrated by Fig. 1, and which, to our knowledge, has not been described previously. This appendage cannot be seen when unstained spores mounted in water are examined under the microscope by ordinary illumination. It is not stained by cotton blue, but is coloured pink with Loeffler's flagella stain and is then clearly visible. When a drop of a spore suspension in water was placed on a microscope slide and allowed to evaporate, it was observed, by phase contrast illumination, that the spores, which had 'tails', stuck to that part of the slide from which the water had receded whereas other spores, which appeared to have no 'tails', were carried along by the receding water. An electron micrograph confirmed tho 